\title{
Metabolic markers following beta-adrenoceptor agonist infusion in footshock-stressed rats
}

\section{J.L. Verago,}

D.M. Grassi-Kassisse and R.C. Spadari-Bratfisch
Departamento de Fisiologia e Biofísica, Instituto de Biologia,

Universidade Estadual de Campinas, Campinas, SP, Brasil

\section{Correspondence \\ R.C. Spadari-Bratfisch \\ Departamento de Fisiologia e \\ Biofísica \\ Instituto de Biologia, UNICAMP \\ 13081-970 Campinas, SP \\ Brasil \\ Fax: + 55-19-289-3124 \\ E-mail: rspabrat@obelix.unicamp.br \\ Publication supported by FAPESP. Part of a Master's thesis presented \\ by J.L. Verago to the Departamento de Fisiologia e Biofísica, Instituto de Biologia, UNICAMP, Campinas, SP, Brazil.}

Received August 25, 2000

Accepted May 31, 2001

\section{Abstract}

Stress hormones can alter metabolic functions in adipose tissue and liver, as well as the sensitivity of rat white adipocytes and rat atrial responses to $\beta$-adrenergic agonists. In this study, we examined the effects of three daily footshock stress sessions on the plasma corticosterone, glucose, glycerol and triacylglycerol levels of fed, conscious male rats, and on the plasma glucose, glycerol and triacylglycerol levels of the same rats following $i v$ infusions of $\beta$-adrenergic agonists (isoproterenol: $0.4 \mathrm{nmol} \mathrm{kg}{ }^{-1} \mathrm{~min}^{-1}$, noradrenaline: $5.0 \mu \mathrm{g} \mathrm{kg}^{-1} \mathrm{day}^{-1}$, and BRL 37344 ([ \pm$]-[4-(2-[(2-[3-$ chlorophenyl]-2-hydroxyethyl) amino]propyl)phenoxy]acetic acid), a selective $\beta_{3}$-adrenoceptor agonist: $0.4 \mathrm{nmol} \mathrm{kg}{ }^{-1} \mathrm{~min}^{-1}$ ). Plasma corticosterone levels increased significantly after each stress session, while triacylglycerol levels increased after the first session and glucose increased after the second and third sessions. Glycerol levels were unaltered after stress. These results suggest that repeated footshock stress may induce a metabolic shift from triacylglycerol biosynthesis to glucose release by hepatic tissue, with glycerol serving as one of the substrates in both pathways. Stressed rats were more sensitive to infusion of noradrenaline plus prazosin and to infusion of isoproterenol, with elevated plasma glucose, glycerol and triacylglycerol levels. The higher sensitivity of stressed rats to isoproterenol and noradrenaline was probably related to the permissive effect of plasma corticosterone. Only BRL 37344 increased plasma glycerol levels in stressed rats, probably because $\beta_{3^{-}}$ adrenoceptors are not involved in hepatic triacylglycerol synthesis, thus allowing glycerol to accumulate in plasma.

\section{Introduction}

The physiological responses to stressors include cardiovascular, renal, visceral, cutaneous, and metabolic changes (1) in which catecholamines and peptides co-released from the sympathoadrenal system act as crucial mediators (1). Although the stress re-
Key words

- Glucose

- Glycerol

- Triacylglycerol

- Triglycerides

- Beta-adrenergic agonist

- Corticosterone

- Infusion sponse enables the organism under attack to prepare itself quickly for fighting or escaping, prolonged or repeated stress is associated with a variety of disorders, including cardiovascular diseases such as hypertension, myocardial infarction, and arteriosclerosis, as well as metabolic diseases such as diabetes (2). The mechanisms by which stress 
affects glucose and lipid metabolism continue to be of great interest, but no consensus has emerged. It is accepted that the central nervous system plays an important role in the regulation of hepatic glucose and lipid metabolism via the sympathetic nervous system and cytokines (2). However, the precise relationship between stress-induced increments in metabolic hormones and in the sensitivity of tissues to catecholamines during repeated or prolonged stress has not been demonstrated in vivo.

Several experimental models have been used to elucidate stress mechanisms, including novelty, water immersion (3), immobilization (4,5), swimming (6), and footshock (7-9). Using a footshock stress paradigm (7), we demonstrated that $B$-adrenergic receptor signaling was altered in cardiac and adipose tissues of stressed rats (6-10). Altered myocardial adrenergic receptor signaling has been demonstrated in several models of cardiac disease such as heart failure $(11,12)$ and ischemic heart disease (12), and these pathologies had been associated with stress (13). Although $\beta_{1^{-}}, \beta_{2^{-}}$, and $\beta_{3^{-}}$-adrenoceptors use the same intracellular signaling pathway, it is now accepted that signaling through one or another subtype is fundamentally different (12) and may involve unknown intracellular pathways.

Since these results were obtained for isolated tissues, the question of the physiological relevance of these stress-induced alterations in the organism in general remains to be answered. The effect of stress on glucose metabolism following electrical stimulation of the sympathetic nerves and the infusion of catecholamines, glucagon, or corticosterone in dogs has been examined (14). Yamada et al. (5) reported that in fed rats, glucagon and corticosterone as well as epinephrine act as synergistic factors to cause stress-induced hyperglycemia. Moreover, in stress situations, lipolysis was greatly stimulated, with an accompanying increase in reesterification to remove the excess free fatty acids released
$(15,16)$.

In the present study, we examined the effect of stress on the functional responses of conscious rats to $B$-adrenoceptor agonist infusion. The plasma levels of corticosterone before and after three sessions of footshock stress were used as indicators of stress intensity, whereas the plasma levels of glucose, triacylglycerol and glycerol were used as indicators of stress-induced substrate mobilization. Following the initial measurements, rats received an iv infusion of noradrenaline, isoproterenol or BRL 37344 ([ \pm$]$ [4-(2-[(2-[3-chlorophenyl]-2-hydroxyethyl) amino]propyl)phenoxy]acetic acid), a selective $\mathrm{B}_{3}$-adrenoceptor agonist, and the above parameters were again determined to evaluate whether the response was altered after stress.

\section{Material and Methods}

\section{Animals}

Male Wistar rats (Rattus norvegicus) weighing 250 to $350 \mathrm{~g}$ at the beginning of the experiments were used. The animals were housed in individual cages $(30 \times 18 \times 20 \mathrm{~cm})$ in a temperature-controlled room $\left(22^{\circ} \mathrm{C}\right)$, on a 12-h light/dark cycle with lights on at 6:30 am. Standard laboratory chow and tap water were available ad libitum. During the experiments, the animals were cared for in accordance with the principles for the use of animals in research and education, as specified in the Statement of Principles adopted by the Federation of the American Societies for Experimental Biology Board. The experimental protocols were also approved by the Institutional Committee for Ethics in Animal Experimentation.

\section{Blood vessel catheterization}

The rats were anesthetized with xylazine $(50 \mathrm{mg} / \mathrm{kg})$ and ketamine $(0.01 \mathrm{mg} / \mathrm{kg})$, and the left carotid artery was cannulated with 
PE20 tubing connected to PE50 tubing that was exteriorized in the dorsal interscapular region where it was fixed to the animals' skin (17). This method permitted the collection of blood samples from unanesthetized, undisturbed freely moving rats. The catheters were siliconized and filled with sodium citrate $(5 \mathrm{mM})$ prior to insertion. In rats which received a drug infusion, the left jugular vein was also cannulated.

\section{Control procedure}

On the first day of the experiment, each rat was placed in the footshock cage where it remained for $30 \mathrm{~min}$ before being returned to the animal care facilities. During this period, the power for the footshock cage was turned off (day 0). On the following three days, this procedure was repeated with each rat in the control group, whereas the rats in the stress group received shocks as described below. Some rats were cannulated to be used as blood donors.

\section{Stress procedure}

Each rat underwent three daily sessions of unsignaled, inescapable footshocks. The animals were placed in a Plexiglas chamber $(26 \times 21 \times 26 \mathrm{~cm})$ provided with a grid floor made of stainless-steel rods $(0.3 \mathrm{~cm}$ in diameter and spaced $1.0 \mathrm{~cm}$ apart). During the 30min sessions, which occurred between 7:30 and 11:00 am, the footshocks were delivered by a constant current source controlled by a microprocessor-based instrument constructed at the University's Biomedical Engineering Center. Current intensity was 1.0 $\mathrm{mA}$ and duration was $1.0 \mathrm{~s}$ at random intervals of 5-25 s (mean interval of $15 \mathrm{~s}$ ). The rats were returned to their cages at the end of each footshock session (10-13).

\section{Experiment 1}

The rats remained in the animal care facilities for at least one week before entering the experimental protocol. During this period, the rats were handled for $15 \mathrm{~min}$ on five successive days. The left carotid artery was then cannulated and the animals were allowed to recover from surgery for $48 \mathrm{~h}$ before being used. On each of four consecutive days, the rats were brought to a silent room where they remained for $60 \mathrm{~min}$. A $25-$ $\mathrm{cm}$ long piece of PE50 polyethylene tubing filled with $0.9 \% \mathrm{NaCl}$ was then connected to the external tip of the cannula. Blood samples $(500 \mu \mathrm{l})$ were withdrawn, and the volume was replaced with blood from a donor rat. Immediately after each blood sampling, the cannulas were filled with $5 \mathrm{mM}$ sodium citrate solution and closed. Blood samples were collected each day immediately before and after the rats had been placed in the experimental cage. The rats were returned to the animal care facilities immediately after collection of the second blood sample.

\section{Experiment 2}

In this group cannulation was performed after the second footshock session. On the next day, immediately after the third footshock or control session, a blood sample $(500 \mu \mathrm{l})$ was withdrawn $(-15 \mathrm{~min})$ from the cannulated artery as described above, and the volume replaced with blood collected from a naive donor animal. Another sample was obtained after $15 \mathrm{~min}(0 \mathrm{~min})$, when drug infusion was started. Blood samples were also obtained at 5, 15, 30, 45 and 60 min after starting the infusion which lasted for $30 \mathrm{~min}$.

Using the cannula implanted into the left jugular vein, the rats received one of the following $B$-adrenergic agonists: isoproterenol $\left(0.4 \mathrm{nmol} \mathrm{kg}^{-1} \mathrm{~min}^{-1}\right)$, noradrenaline (5.0 $\left.\mu \mathrm{g} \mathrm{kg}^{-1} \mathrm{~min}^{-1}\right)$, or BRL 37344 (0.4 nmol $\left.\mathrm{kg}^{-1} \mathrm{~min}^{-1}\right)$. Noradrenaline was also infused with prazosin. In this case, immediately after the third session the rats received an intraperitoneal (ip) injection of prazosin $(0.2 \mathrm{mg} /$ 
$\mathrm{kg})$. The infusion of noradrenaline $(5.0 \mu \mathrm{g}$ $\left.\mathrm{kg}^{-1} \min ^{-1}\right)$ plus prazosin $\left(8.3 \mu \mathrm{g} \mathrm{kg}^{-1} \mathrm{~min}^{-1}\right)$ was then started $30 \mathrm{~min}$ later. The dose regime was based on Galitzky et al. (18).

\section{Analytical determinations}

All blood samples were collected into plastic vials in an ice-water bath and immediately centrifuged at $5000 \mathrm{rpm}$ for $10 \mathrm{~min}$ at $4^{\circ} \mathrm{C}$. Aliquots of plasma were removed and stored at $-20^{\circ} \mathrm{C}$ until assayed for plasma corticosterone, glucose, glycerol and triacylglycerol levels. Plasma glucose was measured by the glucose oxidase method (commercial kit, Laborlab S/A, São Paulo, SP, Brazil). Plasma corticosterone was determined by radioimmunoassay (commercial kit, ICN Pharmaceuticals, Inc., Costa Mesa, CA, USA). For glycerol measurements, plasma was deproteinized prior to the enzymatic assay (19). Plasma triacylglycerol levels were also measured by an enzymatic method (commercial kit, Laborlab).

Figure 1. Plasma corticosterone levels of fed conscious rats before and after the control procedure (top) or $30 \mathrm{~min}$ of footshock stress (bottom). On day 0, animals of both groups were placed in the footshock cage but did not receive footshocks (control procedure). On days 1,2 and 3 , rats in the stressed group received 120 footshocks $(1.0 \mathrm{~mA}, 1.0 \mathrm{~s}$ intervals of $5-25 \mathrm{~s}$ between shocks) over a 30-min period. Rats from the control group remained in the footshock cage but did not receive footshocks. The columns represent the means \pm SEM for 5 experiments. $* \mathrm{P}<0.05$ compared to the control group before and after the session on days $0,1,2$ and 3 , and $\mathrm{P}<0.05$ compared to the footshock group before the session on days 0,1 , and 2 . $+P<0.05$ compared to the footshock group before the session on day 2 (ANOVA plus Tukey test).

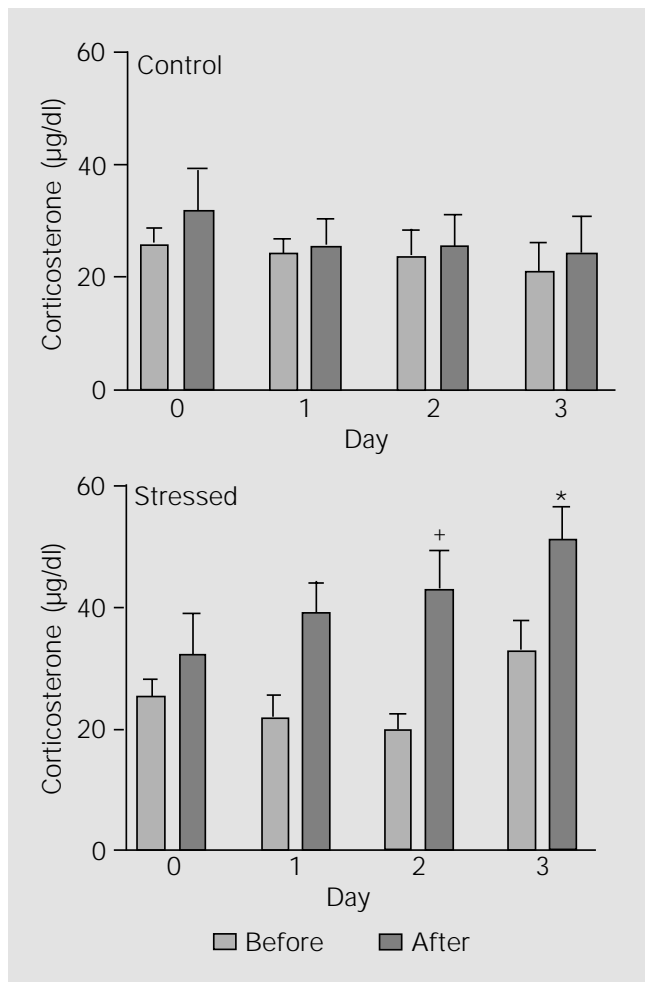

\section{Drugs and chemicals}

ATP, bovine serum albumin (fraction V), glycerol phosphate dehydrogenase type I from rabbit muscle, glycerol kinase from Candida mycoderma, (-)-isoproterenol, (-)-noradrenaline, prazosin $\mathrm{HCl}$ and sodium citrate were from Sigma (St. Louis, MO, USA); BRL 37344 was from Tockris Cookson (Ballwin, MO, USA), xylazine from Bayer S.A. (São Paulo, SP, Brazil), and ketamine from Konig S.A. (São Paulo, SP, Brazil).

\section{Statistical analysis}

The results are reported as means \pm SEM. Differences between the plasma levels of each compound before and after the control or stress procedure during the four successive days of experiment 1 , and between the plasma levels at each time interval during or after drug infusion (experiment 2) were analyzed by two-way ANOVA for repeated measures, followed by the Tukey test. Differences were considered significant for $\mathrm{P}<0.05$.

\section{Results}

\section{Effect of footshock stress on plasma corticosterone, glucose, glycerol and triacylglycerol levels}

Figure 1 shows the plasma corticosterone levels in fed conscious rats before and after the control procedure or footshock stress. There were no differences in the plasma corticosterone levels among any of the control groups. In stressed rats, there was a trend towards an increase in the levels of corticosterone after stress on days 1,2 and 3 . However, ANOVA for repeated measures followed by the Tukey test showed that only on days 2 and 3 were the plasma corticosterone levels after footshock stress significantly higher than those before footshock. Plasma 
corticosterone levels on day 3 were also higher than the levels on days 0 and 1 $(\mathrm{P}<0.05)$.

Figure 2 shows that the plasma glucose, glycerol and triacylglycerol levels in the conbefore or after the control procedure during the four days of the experiment. In the footshock group, the plasma glucose levels on days 2 and 3 increased after footshock compared to the values before footshock $(\mathrm{P}<0.05)$. Furthermore, on day 3 , the plasma glucose levels were higher than all values in the control group and in the footshock stress group, except on day 2 after footshock trol group were not significantly different

$(\mathrm{P}<0.05)$. Plasma glycerol levels were not significantly different before or after the footshock stress on any of the three days. Plasma triacylglycerol levels increased after footshock stress only on day $1(\mathrm{P}<0.05$; Figure $2)$.

\section{Effect of isoproterenol, noradrenaline, noradrenaline plus prazosin, or BRL 37344 infusion on plasma glucose, glycerol and triacylglycerol levels}

After the third footshock session, the rats were kept in their home cages until the plasma glucose levels decreased to values which
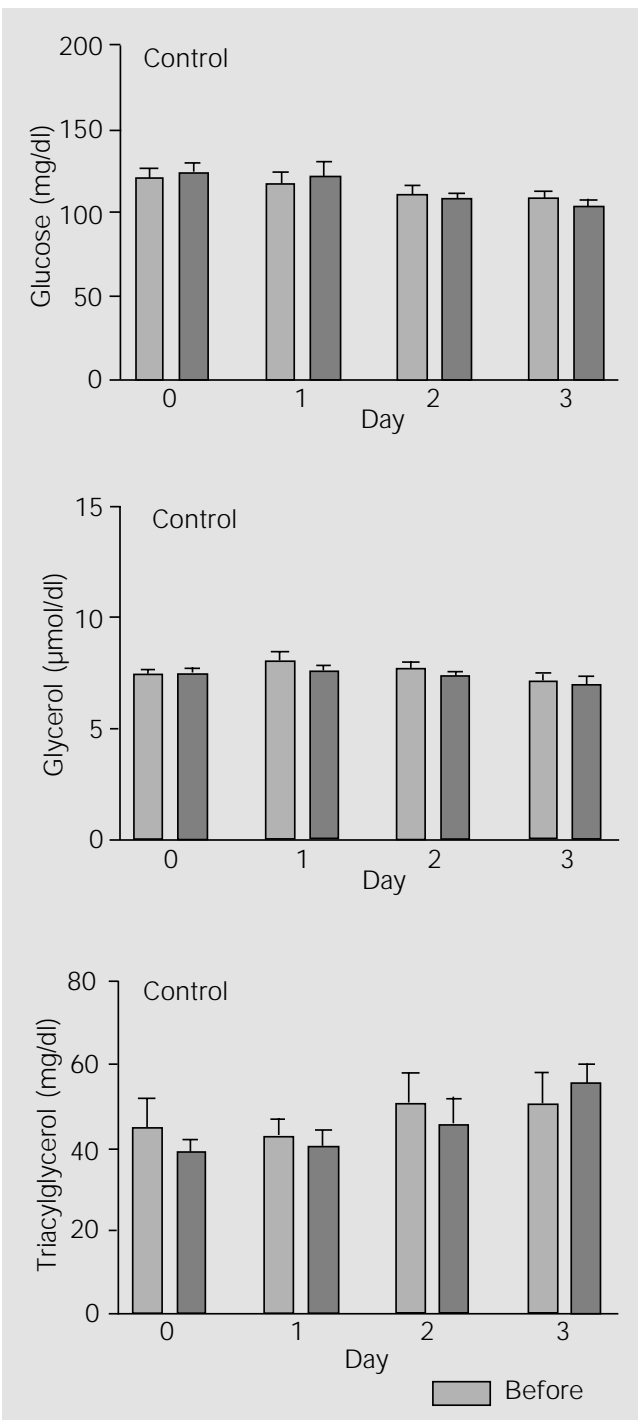
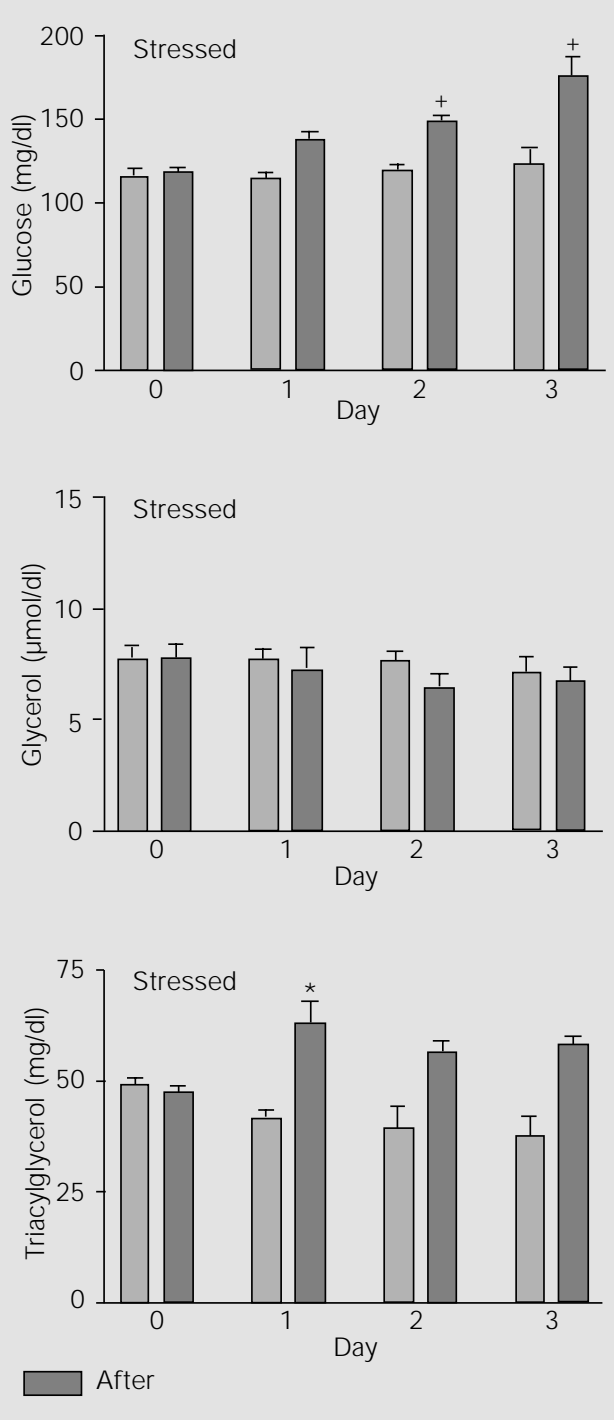

Figure 2. Plasma glucose, glycerol and triacylglycerol levels of fed conscious rats before and after the control procedure (left panels) or 30 min of footshock stress (right panels). On day 0 , animals of both groups were placed in the footshock cage but did not receive footshocks (control procedure). On days 1,2 and 3 , rats in the stressed group received 120 footshocks (1.0 $\mathrm{mA}, 1.0 \mathrm{~s}$, intervals of $5-25 \mathrm{~s}$ between shocks) over a 30-min period. Rats from the control group remained in the footshock cage but did not receive footshocks. The columns represent the means \pm SEM of 5 animals in each group. $+\mathrm{P}<0.05$ compared to the control group before and after the session, and to the footshock group before session (ANOVA plus Tukey test). $* \mathrm{P}<0.05$ compared to the control group after the session and to the footshock group before the session (ANOVA plus Tukey test). 
Figure 3. Effect of iv infusion of saline solution $(0.9 \% \mathrm{NaCl}, \mathrm{w} / \mathrm{v})$ or isoproterenol $\left(0.4 \mathrm{nmol} \mathrm{kg}{ }^{-1}\right.$ $\mathrm{min}^{-1}$ ) on plasma glucose, glycerol and triacylglycerol levels in fed conscious rats after three daily sessions of confinement in footshock cages with no footshocks (control) or with footshock stress for $30 \mathrm{~min}$. The infusion (time 0) began 15 min after the end of the third session. The points represent the means \pm SEM of the number of rats indicated in parentheses. $* \mathrm{P}<0.05$ compared to the control group; $+\mathrm{P}<0.05$ compared to the value at 0 min; **P $<0.05$ compared to the values at 5,15 and $30 \mathrm{~min}$; \#P $<0.05$ compared to the values at $-15,0,5,15$, and $30 \mathrm{~min}$ in the control group (ANOVA plus Tukey test). were not significantly different from basal values (15 min). At this point, an $i v$ infusion of saline solution $(0.9 \% \mathrm{NaCl}, \mathrm{w} / \mathrm{v})$, isoproterenol $\left(0.4 \mathrm{nmol} \mathrm{kg}^{-1} \mathrm{~min}^{-1}\right)$, noradrenaline $\left(5.0 \mu \mathrm{g} \mathrm{kg}^{-1} \mathrm{~min}^{-1}\right)$, or BRL $37344(0.4 \mathrm{nmol}$ $\mathrm{kg}^{-1}$ min $^{-1}$ ) was started.

The infusion of saline solution in control rats did not significantly alter the plasma glucose, glycerol or triacylglycerol levels (Figure 3). Immediately after the third session, plasma glucose levels were higher in stressed rats than in control rats. During the subsequent $15 \mathrm{~min}$, the plasma glucose levels of stressed rats decreased to the levels
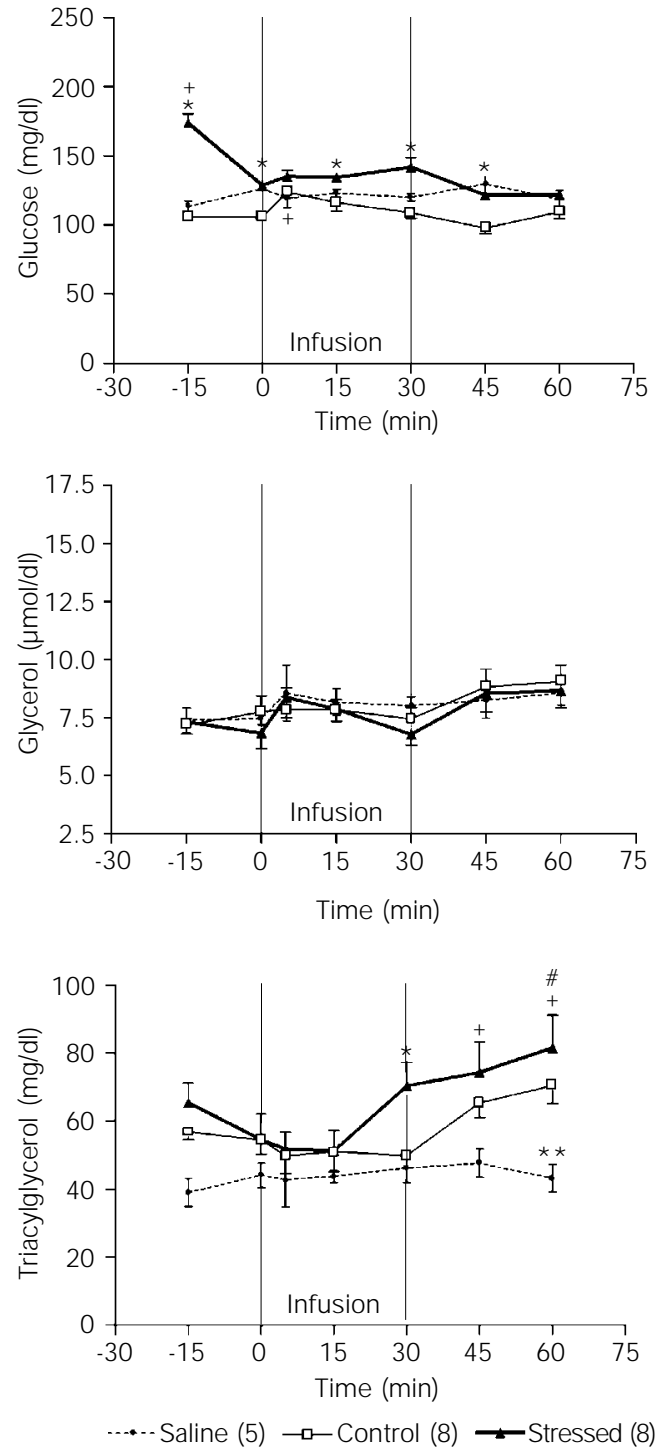

seen in the control rats. In the control group, isoproterenol $\left(0.4 \mathrm{nmol} \mathrm{kg}^{-1} \mathrm{~min}^{-1}\right)$ increased the plasma glucose levels after $5 \mathrm{~min}$ followed by a return to basal values during infusion $(\mathrm{P}<0.05$; Figure 3$)$. In footshockstressed rats, plasma glucose levels were higher than in the controls during infusion and $15 \mathrm{~min}$, but not $30 \mathrm{~min}$, after the end of infusion $(\mathrm{P}<0.05)$. Isoproterenol had no effect on the plasma glycerol levels of control or footshocked rats (Figure 3). In control rats, isoproterenol increased the plasma triacylglycerol levels only $60 \mathrm{~min}$ after the start of the infusion (30 min after the end), whereas in footshock-stressed rats the increase in plasma triacylglycerol levels was significant at 30, 45 and 60 min after the onset of the infusion compared to the values obtained immediately before infusion $(\mathrm{P}<0.05$; Figure 3).

Noradrenaline $\left(5.0 \mu \mathrm{g} \mathrm{kg}^{-1} \mathrm{~min}^{-1}\right)$ had no significant effect on plasma glucose or glycerol levels in either group (Figure 4). Noradrenaline produced a similar profile of variation in the plasma triacylglycerol levels of control and footshock-stressed rats (Figure 4), with the levels of triacylglycerol being significantly lower in stressed rats than in control rats $15 \mathrm{~min}$ after the start of the infusion and 30 min after the end of infusion (Figure 4). Since noradrenaline has a potent vasoconstrictor effect that might affect the release and/or clearance of substrates in several tissues, we examined the effects of noradrenaline in rats which received prazosin before and during noradrenaline infusion.

An ip injection of prazosin did not affect the plasma glucose, glycerol or triacylglycerol levels in control rats (Figure 5). However, in stressed rats which received prazosin, the plasma glucose levels remained high during the $30 \mathrm{~min}$ following ip injection of prazosin, so that when the infusion started the levels were higher in stressed rats than in control rats (Figure 5).

When the infusion of noradrenaline plus prazosin started, there was no significant 
increase in plasma glucose levels in control or stressed rats. At the end of infusion, glucose levels tended to decrease towards preinfusion levels, although the values in the stressed rats were higher than in control rats, even 30 min after the end of infusion (Figure 5). Similar trends were observed for plasma glycerol levels. However, there was a peak in the plasma glycerol levels of stressed rats 15 min after the end of infusion, when triacylglycerol levels were higher in stressed rats than in control rats (Figure 5).

BRL $37344\left(0.4 \mathrm{nmol} \mathrm{kg}^{-1} \mathrm{~min}^{-1}\right)$ had no significant effect on plasma glucose or triacylglycerol levels in either group of rats (Figure 6). BRL 37344 infusion also had no significant effect on plasma glycerol levels in control rats (Figure 6) but increased these levels in footshock-stressed rats towards the end of infusion ( $30 \mathrm{~min}$ ) followed by a return to basal levels after the infusion had ended (Figure 6).

\section{Discussion}

An increase in plasma corticosterone in response to stress is directly related to the stressor intensity, so that corticosterone is a useful indicator $(3,20)$. Plasma catecholamines also increase during the stress reaction $(3,21)$.

Figure 1 shows that $48 \mathrm{~h}$ after surgery, the plasma corticosterone level of rats was $26.1 \pm 2.7 \mu \mathrm{g} / \mathrm{dl}$. This value was significantly higher than the previously reported level of $13.0 \pm 0.3 \mu \mathrm{g} / \mathrm{dl}$ for male rats sedated with sodium pentobarbital (8) but was similar to that measured by De Boer et al. $(3,20)$ in fed rats transferred to a novel cage and environment, as done here. Thus, high plasma corticosterone levels appear to be typical of conscious rats brought to a different environment and sampled for blood collection while freely moving in the cage. Confinement in a footshock cage for $30 \mathrm{~min}$ without receiving any footshock did not alter the plasma corticosterone levels, indicating that remaining in a novel room for $30 \mathrm{~min}$ was not an additional stressor stimulus. However, when rats received footshocks, plasma corticosterone levels increased, as expected, and repetition of the stressor stimulus caused a more pronounced response, indicating that animals had not adapted to the stressor. Many authors have shown that plasma corticosterone responses are reduced in rats following repeated presentation of noise $(21,22)$, handling (23), novelty $(24,25)$ or restraint $(26)$, whereas with the use of relative intense stressors such as footshock (27), cold exposure (27), forced running $(27,28)$ or a combina-
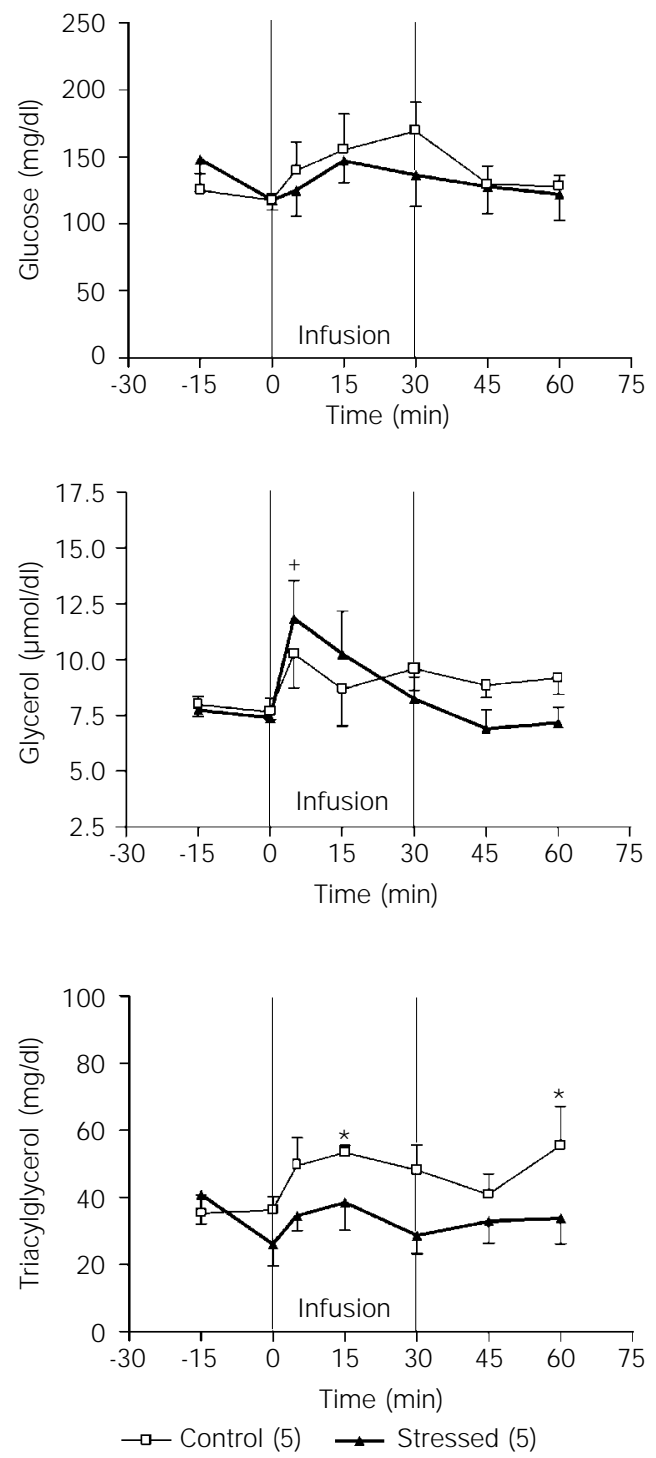

Figure 4. Effect of iv infusion of noradrenaline $\left(5.0 \mu \mathrm{g} \mathrm{kg}^{-1} \mathrm{~min}^{-1}\right)$ on plasma glucose, glycerol and triacylglycerol levels in fed conscious rats after three daily sessions of confinement in footshock cages with no footshocks (control) or with footshock stress for $30 \mathrm{~min}$. The infusion (time 0) began $15 \mathrm{~min}$ after the end of the third session. The points represent the means \pm SEM of the number of rats indicated in parentheses. ${ }^{+} \mathrm{P}<0.05$ compared to the value at $45 \mathrm{~min}$; $* \mathrm{P}<0.05$ compared to the values at 0 and $30 \mathrm{~min}$ for the footshock group (ANOVA plus Tukey test). 
Figure 5. Effect of iv infusion of noradrenaline $\left(5.0 \mu \mathrm{g} \mathrm{kg}^{-1} \mathrm{~min}^{-1}\right)$ plus prazosin $\left(8.3 \mathrm{\mu g} \mathrm{kg}^{-1} \mathrm{~min}^{-1}\right)$ on plasma glucose, glycerol and triacylglycerol levels in fed conscious rats after three daily sessions of confinement in footshock cages with no footshocks (control) or with footshock stress for $30 \mathrm{~min}$. The rats received 0.2 $\mathrm{mg}$ of prazosin/kg, ip, immediately after the third session. The infusion of noradrenaline began 30 min after the end of the third session. The points represent the means \pm SEM of the number of rats indicated in parentheses. $* \mathrm{P}<0.05$ compared to the value for the control group: **P $<0.05$ compared to the values at -15 and 0 min for the control group; $+\mathrm{P}<0.05$ compared to the value at $0 \mathrm{~min}$; ${ }^{\mathrm{P}}<0.05 \mathrm{com}$ pared to the values at all other time points, except for $45 \mathrm{~min}$ in the control group (ANOVA plus Tukey test). tion of restraint, light, noise and tailcutting (29), no such adaptation was detected. Our stressed rat model presented higher plasma corticosterone levels before the second and third footshock sessions compared to control rats, indicating that with repetition of the stressful stimulus some anticipation rather than adaptation to the stressor may occur.

Plasma glucose levels followed a pattern similar to that of plasma corticosterone levels. In footshock-stressed rats, the glucose levels increased significantly after the second and third stress sessions (Figure 2). This probably reflects the permissive effect of corticosterone on the action of catechol-
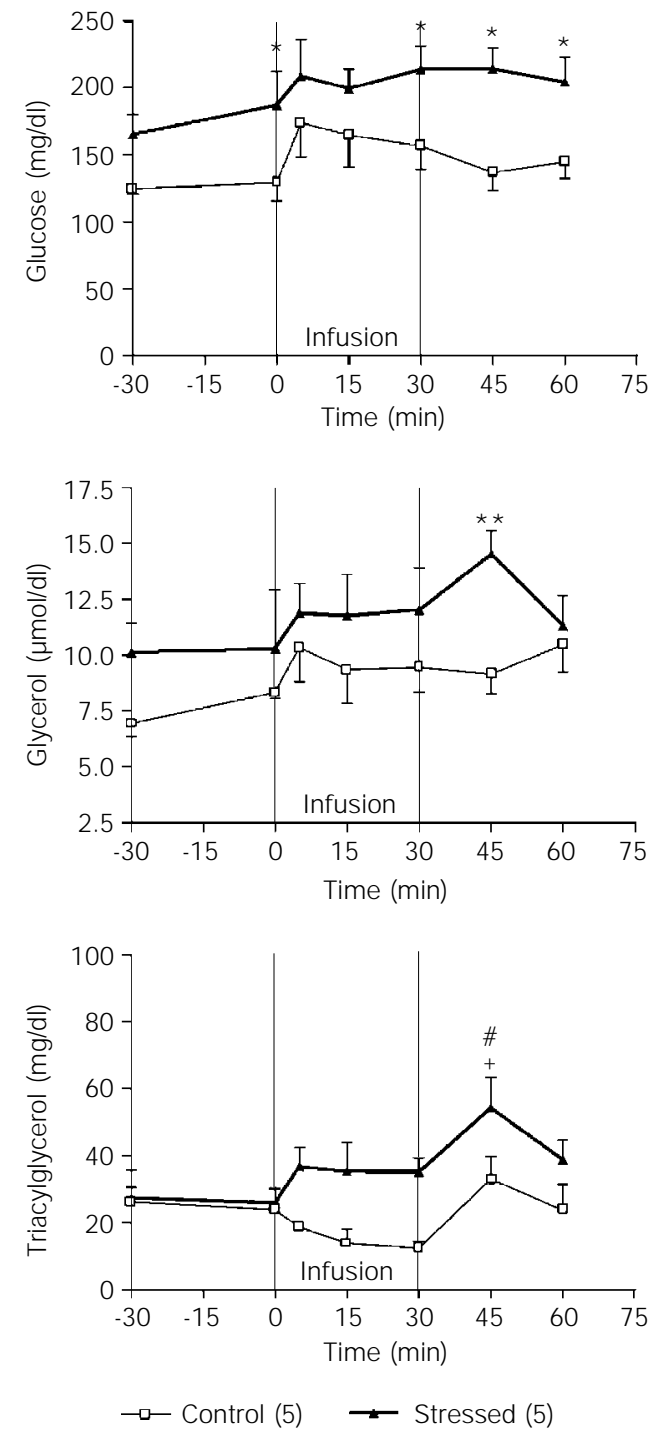

amines plus the effect of glucagon in stimulating gluconeogenesis and glycogenolysis in hepatic cells $(2,30)$ and the $\alpha$-adrenergic effects of endogenous catecholamines in inhibiting insulin secretion (31). In contrast to plasma glucose, which increased progressively with the repetition of stress, plasma triacylglycerol levels were not enhanced on day 2 or 3 but were significantly higher than control after the first footshock session (Figure 2). Although we did not measure any hepatic function indicators, this result suggests that, as the stress is repeated, glucose is released by the liver instead of triacylglycerol. The use of glycerol released by adipose tissue as a gluconeogenic substrate may help to maintain the plasma glycerol level unchanged after stress despite the adrenergic stimulation of lipolysis in white adipose tissue (32). Taken together, these findings indicate that repeated stress leads to a widespread or general metabolic response aimed at maintaining high plasma glucose levels. This post-stress hyperglycemia is enhanced by repetition of the stressful stimulus, suggesting a sensitization of this response.

Because we have previously shown that after this same stress protocol cardiac tissue and adipocytes are supersensitive to isoproterenol and subsensitive to noradrenaline $(7,8)$ and to BRL 37344 (8), we examined the effect of an infusion of these compounds on plasma glucose, glycerol and triacylglycerol levels in stressed rats.

In control rats, the infusion of isoproterenol increased glycemia, which peaked by the fifth minute, followed by a slow decrease towards the basal value during infusion. This time course is probably a consequence of the effect of isoproterenol on hepatic glycogenolysis and gluconeogenesis followed by insulin secretion (33). In footshock-stressed rats, the glycemia during isoproterenol infusion was higher than in control rats, indicating that glycogenolysis and gluconeogenesis were also higher in these animals. Since De Boer et al. $(3,20)$ have shown that in control 
rats brought to a novel room the plasma noradrenaline and adrenaline levels had already returned to basal values by the end of a 30-min period, this effect observed in stressed rats seems to be a consequence of the high levels of endogenous catecholamine (34) or of stress-induced insulin resistance (35). Since isoproterenol stimulated lipolysis (36) as well as insulin release, plasma glycerol could be used by the liver for triacylglycerol synthesis, thereby maintaining the plasma glycerol levels unchanged, despite an increase in lipolysis. Furthermore, the late permissive effects of corticosterone on the action of endogenous catecholamine may have enhanced this metabolic pathway, since in stressed rats the increase in plasma triacylglycerol levels was faster and higher than in control rats.

Although noradrenaline has glycogenolytic and gluconeogenic effects in isolated hepatocytes and lipolytic effects in isolated adipocytes, when infused in rats its vasoconstrictor effect in vivo may mask its metabolic action (37). This may explain why there were no significant changes in plasma glucose or glycerol levels in the control and stressed rats infused with noradrenaline. In control rats, the plasma glucose levels were not modified by the $\alpha_{1}$-adrenoceptor antagonist, prazosin, but increased during the initial 5 min of noradrenaline plus prazosin infusion, slowly decreasing towards basal levels during and after infusion. However, when rats received prazosin (Figure 5) immediately after the third footshock session, the glycemia remained high before and throughout the period of noradrenaline plus prazosin infusion and up to $30 \mathrm{~min}$ after the end of the infusion. Thus, the $\beta$-adrenoceptormediated effect of noradrenaline observed in the presence of prazosin was similar to the effect of isoproterenol (Figure 3), a selective B-adrenoceptor agonist, and was more pronounced in stressed than in control rats.

The time course of changes in plasma triacylglycerol levels induced by the infu- sion of noradrenaline was similar in control and stressed rats. The effect of noradrenaline in the presence of prazosin differed between stressed and control rats, with the former being more sensitive to this catecholamine than to isoproterenol.

Tissues from stressed rats are supersensitive to adrenaline $(2,7)$, which is elevated in stressed rats, and to isoproterenol (7). However, subsensitivity to noradrenaline has been reported in cardiac tissue and adipocytes from stressed rats $(7,8)$. In vivo conditions are much more complex and involve several factors which are difficult to control. Even if isolated tissues were subsensitive to nor-
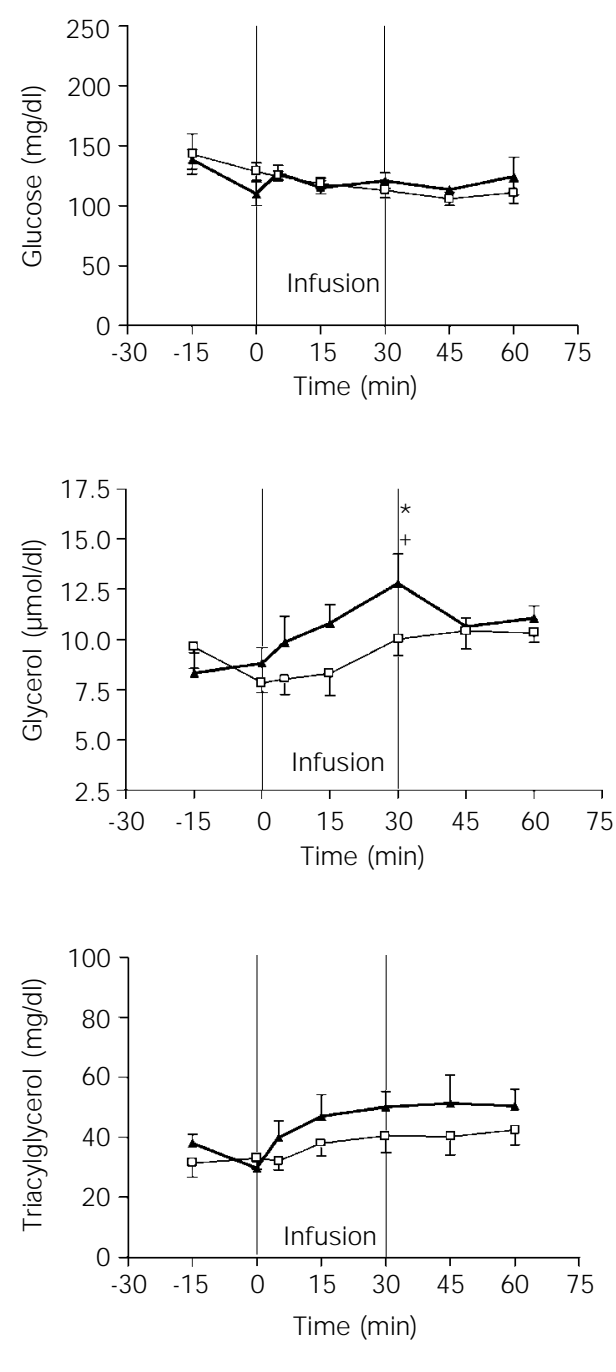

$\neg-$ Control (7) $\rightarrow$ Stressed (7)
Figure 6. Effect of iv infusion of BRL $37344\left(0.4 \mathrm{nmol} \mathrm{kg} \mathrm{min}^{-1}\right)$ on plasma glucose, glycerol and triacylglycerol levels in fed conscious rats after three daily sessions of confinement in footshock cages with no footshocks (control) or with footshock stress for $30 \mathrm{~min}$. BRL 37344 infusion began 30 min after the end of the third session. The points represent the means \pm SEM of the number of rats indicated in parentheses. $+P<0.05$ compared to the value at $0 \mathrm{~min}$; $* \mathrm{P}<0.05$ compared to the values at 0,5 and $15 \mathrm{~min}$ in the control group (ANOVA plus Tukey test). 
adrenaline, this stress-induced subsensitivity seems not to be sufficient to overcome the combined effect of the high levels of endogenous catecholamines plus the infused exogenous noradrenaline.

BRL 37344 is a selective $\beta_{3}$-adrenoceptor agonist $(38,39)$ which stimulates lipolysis in rat white adipocytes (39) and insulin secretion by pancreatic islets (38), but has no effect on hepatic triacylglycerol synthesis (40). The infusion of BRL 37344 did not alter the plasma glucose levels of control or stressed rats. However, this compound induced a more pronounced increase of plasma glycerol levels in stressed than in control rats. Again, the adipocyte subsensitivity to BRL 37344 demonstrated in vitro seems to be overcome by the high plasma corticosterone and catecholamine levels of stressed rats.

Our results suggest that stress caused by repeated footshock may induce metabolic changes leading to glucose production instead of triacylglycerol biosynthesis. This pathway probably involves the use of glycerol as a substrate. The in vivo responses to the infusion of isoproterenol, noradrenaline and BRL 37344 were more pronounced in stressed rats than in control rats.

\section{References}

1. Nankova B, Kvetnansky R, Hiremagalur B, Sabban B, Rusnak M \& Sabban EL (1996). Immobilization stress elevates gene expression for catecholamine biosynthetic enzymes and some neuropeptides in rat sympathetic ganglia: effects of adrenocorticotropin and glucocorticoids. Endocrinology, 137: 5597-5604.

2. Nonogaki K (2000). New insights into sympathetic regulation of glucose and fat metabolism. Diabetologia, 43: 533-549.

3. De Boer SF, Koopmans SJ , Slanger J L \& Van Der Gugten J (1990). Plasma catecholamine, corticosterone and glucose responses to repeated stress in rats: effect of interstressor interval length. Physiology and Behavior, 47: 1117-1124.

4. Kvetnansky R, Nankova B, Hiremagalur B, Viskupic E, Vietor I, Rusnak M, McMahon A, Kopin IJ \& Sabban EL (1996). Induction of adrenal tyrosine hydroxylase mRNA by single immobilization stress occurs even after splanchnic transection and in the presence of cholinergic antagonists. J ournal of Neurochemistry, 66: 138-146.

5. Yamada F, Inoue S, Saitoh T, Tanaka K, Satoh S \& Takamura Y (1993). Glucoregulatory hormones in the immobilization stress-induced increase of plasma glucose in fasted and fed rats. Endocrinology, 132: 2199-2205.

6. Marcondes FK, Vanderlei LCM, Lanza LLB \& Spadari-Bratfisch RC (1996). Stress-induced subsensitivity to catecholamines depends on the estrous cycle. Canadian J ournal of Physiology and Pharmacology, 74: 663-669.
7. Vanderlei LCM, Marcondes FK, Lanza LLB \& Spadari-Bratfisch RC (1996). Influence of the estrous cycle on the sensitivity to catecholamines in right atria from rats submitted to foot-shock stress. Canadian J ournal of Physiology and Pharmacology, 74: 670-678.

8. Farias-Silva $E$, Grassi-Kassisse DM, WolfNunes V \& Spadari-Bratfisch RC (1999). Stress-induced alteration in the lipolytic response to beta-adrenoceptor agonists in rat white adipocytes. J ournal of Lipid Research, 40: 1719-1727.

9. Spadari-Bratfisch RC, Santos IN, Vanderlei LCM \& Marcondes FK (1999). Pharmacological evidence for $B_{2}$-adrenoceptor in right atria from stressed female rats. Canadian J ournal of Physiology and Pharmacology, 77: 432-440.

10. Spadari RC \& De Moraes S (1988). Repeated swimming stress and responsiveness of the isolated rat pacemaker to the chronotropic effects of noradrenaline and isoproterenol: role of adrenal corticosteroids. General Pharmacology, 19: 553557.

11. Brodde OE (1993). Beta-adrenoceptors in cardiac disease. Pharmacology and Therapeutics, 60: 405-443.

12. Koch WJ, Lefkowitz RJ \& Rockman HA (2000). Functional consequences of altering myocardial adrenergic receptor signaling. Annual Review of Physiology, 62: 237-260.

13. Goldstein DS (1995). Stress, Catecholamines and Cardiovascular Diseases. Oxford University Press, Inc., New York.
14. Eigler N, Sacca L \& Sherwin RS (1979). Synergistic interactions of physiologic increments of glucagon tumover in the dog. American J ournal of Physiology, 235: E287-E290.

15. Wolfe RR, Klein S, Hemdon DN \& J ahoor $F(1990)$. Substrate cycling in thermogenesis and amplification of net substrate flux in human volunteers and burned patients. J oumal of Trauma, 30: S6-S9.

16. Coppack SW, J ensen MD \& Miles JM (1994). In vivo regulation of lipolysis in humans. J ournal of Lipid Research, 35: 177-193.

17. Popovic V \& Popovic P (1960). Permanent cannulation of aorta and vena cava in rats and ground squirrels. J oumal of Applied Physiology, 15: 727-728.

18. Galitzky J, Reverte $M$, Carpéné $C$, Lafon$\tan$ M \& Berlan M (1993). B3-adrenoceptors in dog adipose tissue: studies on their involvement in the lipomobilizing effect of catecholamines. J ournal of Pharmacology and Experimental Therapeutics, 266: 358-366.

19. Wieland O (1957). Eine enzymatische Methode zur Bestimmung von Glycerin. Biochemische Zeitschrift, 329: 313-319.

20. De Boer SF, Koopmans SJ , Slanger J L \& Van Der Gugten J (1989). Effects of fasting on plasma catecholamine, corticosterone and glucose concentrations under basal and stress conditions in individual rats. Physiology and Behavior, 45: 989-994.

21. Konarska M, Stewart RE \& McCarty R (1990). Habituation of sympathetic-adrenal medullary responses following expo- 
sure to chronic intermittent stress. Physiology and Behavior, 47: 647-652.

22. Armario A, Castellanos J M \& Balasch J (1984). Adaptation of anterior pituitary hormones to chronic noise stress in rats. Behavioral and Neural Biology, 41: 71-76.

23. Dobrakovova M \& J uricovicova J (1984). Corticosterone and prolactin responses to repeated handling and transfer of male rats. Experimental and Clinical Endocrinology and Diabetes, 83: 21-27.

24. Basset JR, Cairncross KD \& King MG (1973). Parameters of novelty, shock predictability and response contingency in corticosterone release in the rat. Physiology and Behavior, 10: 901-907.

25. Pfister HP (1979). The glucocorticosterone response to novelty as a psychological stressor. Physiology and Behavior, 23: 649-652.

26. Pitman DL, Ottenweller JE \& Natelson BH (1988). Plasma corticosterone levels during presentation of two intensities of restraint stress: chronic stress and habituation. Physiology and Behavior, 43: 47-55.

27. Kant GJ , Egglestone T, Landman-Roberts L, Kenion CC, Driver GC \& Meyerhoff J L (1985). Habituation to repeated stress is stressor specific. Pharmacology, Biochemistry and Behavior, 22: 631-634.

28. Kant GJ, Bunnell BN, Mougey EH, Pennington LL \& Meyerhoff JL (1983). Effects of repeated stress on pituitary cyclic AMP, and plasma prolactin, corticosterone and growth hormone in male rats. Pharmacology, Biochemistry and
Behavior, 18: 967-971.

29. Murison R, Overmier J B \& Skoglund EJ (1986). Serial stressors: prior exposure to a stressor modulates its later effectiveness on gastric ulceration and corticosterone release. Behavioral and Neural Biology, 45: 185-195.

30. Exton J H, Friedman $\mathrm{N}$, Hee-Aik Hong $\mathrm{E}$, Brineaux P, Corbin J D \& Park CR (1972). Interaction of glucocorticoids with glucagon and epinephrine at the control of gluconeogenesis and glycogenolysis in liver and of lipolysis in adipose tissue. J ournal of Biological Chemistry, 247: 3579-3588.

31. Porte D \& Robertson RP (1973). Control of insulin secretion by catecholamines, stress and the sympathetic nervous system. Federation Proceedings, 32: 17921796.

32. Wolfe RR, Shaw JH \& Durkot MJ (1983). Energy metabolism in trauma and sepsis: the role of fat. Progress in Clinical and Biological Research, 111: 89-109.

33. J ohn GW, Doxey J C, Walter DS \& Reid J L (1990). The role of alpha- and betaadrenoceptor subtypes in mediating the effects of catecholamines on fasting glucose and insulin concentrations in the rat. British J oumal of Pharmacology, 100: 699704.

34. Pilkis SJ \& El-Maghrabi MR (1988). Hormonal regulation of hepatic gluconeogenesis and glycolysis. Annual Review of Biochemistry, 57: 755-783.

35. Chaouloff $F$, Laude $D$, Merino $D$, Semurier B \& Elghozi J L (1989). Peripheral and cen- tral consequences of immobilization stress in genetically obese Zucker rats. American J ournal of Physiology, 256: R435-R442.

36. Van Liefde I, Van Witzenburg A \& Vauquelin G (1992). Multiple beta adrenergic receptor subclasses mediate the Iisoproterenol-induced lipolytic response in rat adipocytes. J ournal of Pharmacology and Experimental Therapeutics, 262: 552-558.

37. Guimarães S (1986). Postsynaptic alphaadrenoceptors in blood vessels: discrepancies between results obtained in vivo and in vitro. In: Grobecker H, Philippou K $\&$ Starke K (Editors), New Aspects of the Role of Adrenoceptors in the Cardiovascular System. Springer-Verlag, Berlin, Heidelberg, Munich.

38. Yoshida $T$ (1992). The antidiabetic beta-3adrenoceptor agonist BRL $26830^{\mathrm{A}}$ works by release of endogenous insulin. American J ournal of Clinical Nutrition, 55: 237S2415.

39. Atef $\mathrm{N}$, Lafontan $\mathrm{M}$, Double A, Helary $\mathrm{C}$, Ktorza A \& Penicaud L (1996). A specific beta 3-adrenoceptor agonist induces increased pancreatic islet blood flow and insulin secretion in rats. European J ournal of Pharmacology, 298: 287-292.

40. Evans BA, Papaioannou M, Bonazzi VR \& Summers RJ (1996). Expression of beta 3-adrenoceptor mRNA in rat tissues. British J oumal of Pharmacology, 117: 210216. 